\title{
FINANCIAMENTO E DIVERSIDADE PRODUTIVA: UM MODELO BASEADO EM AGENTES COM FLUTUAÇÕES CÍCLICAS EMERGENTES ${ }^{*}$
}

\author{
Teófilo Henrique Pereira de Paula \\ Marco Crocco ${ }^{b}$
}

\begin{abstract}
RESUMO: As abordagens que consideram os choques externos como causa principal das flutuações econômicas têm dominado o debate sobre o tema. De fato, a ideia de que instabilidades podem se originar endogenamente sempre esbarrou em dificuldades de formalização ao pressupor a existência de processos não lineares e cumulativos como intrínsecos ao sistema econômico. Recentemente, a utilização de ferramentas computacionais tem permitido a superação de muitos desses obstáculos. Nessa perspectiva, o presente trabalho tem como objetivo analisar o comportamento agregado de um sistema econômico caracterizado pela interação entre unidades individuais heterogêneas que tomam decisões de forma descentralizada em um ambiente incerto. A metodologia utilizada se baseia na construção e na implementação computacional de um modelo de simulação baseado em agentes (agent-based model). Particularmente, uma estrutura industrial com diferenciação assimétrica de produtos é conectada a um sistema financeiro por meio do mercado de crédito. Dentre os principais resultados, crises financeiras com características bastante próximas daquelas descritas por Minsky emergem da evolução do sistema.
\end{abstract}

PALAVRAS-CHAVE: Agentes; moeda; diferenciação de produtos; incerteza.

CLASSIFICAÇÃO JEL: E12; L00; C63.

Artigo recebido em 05/11/2011 e aprovado em 07/12/2012.

a Doutor em Economia pelo Centro de Desenvolvimento e Planejamento Regional da Universidade Federal de Minas Gerais (CEDEPLAR/UFMG) e professor adjunto da Universidade Federal Rural do Rio de Janeiro. Contato: teohpaula@gmail.com.

b PhD em Economia pela University of London e professor associado do CEDEPLAR/UFMG. Contato: crocco@cedeplar.ufmg.br. 


\section{FINANCING AND PRODUCTIVE DIVERSITY: AN AGENT-BASED MODEL WITH EMERGENT CYCLIC FLUCTUATIONS}

ABSTRACT: External shocks as the major cause of economic fluctuations have dominated the debate in economic theory. In fact, propositions based on endogenous explanation of instabilities always found difficulties in formalization, basically by considering nonlinearities and cumulativeness as intrinsic characteristics of the economic system. Recently, however, the use of computational tools has increasingly allowed overcoming these obstacles. In this context, the paper aims at analyzing the aggregate behavior of an economic system characterized by interaction between heterogeneous agents, which take decisions in a decentralized way and subject to uncertainty. The methodology is based on construction and computational implementation of an agent-based model. Specifically, an industrial structure with asymmetric product differentiation is linked to a financial system based on credit. Among the results, financial crises, similar to that proposed by Minsky, emerge from the system evolution.

KEYWORDS: Agents; money; product differentiation; uncertainty. 


\section{INTRODUÇÃO}

As abordagens que consideram os choques externos como causa principal das flutuações econômicas têm dominado o debate econômico sobre o tema. Espaço menor tem ocupado proposições que enfatizam processos cumulativos gerados endogenamente e que podem resultar em instabilidade sistêmica. O presente trabalho constitui uma tentativa de explorar essa perspectiva. A partir da hipótese de que "a moeda importa", desenvolve-se um modelo em que se estabelece uma conexão entre uma estrutura industrial, caracterizada por diferenciação assimétrica de produtos ${ }^{1}$, concorrência imperfeita e economias de escala e um sistema financeiro baseado no crédito, cujo comportamento é essencialmente especulativo. Pretende-se avaliar as condições que possibilitam a emergência de flutuações macroeconômicas, considerando-se o comportamento individual de agentes que operam em um sistema descentralizado e com ausência de um leiloeiro walrasiano. Propõe-se que tais objetivos possam ser alcançados via simulações computacionais, a partir de modelos baseados em agentes, construídos bottom-up ${ }^{2}$.

$\mathrm{O}$ trabalho se divide em quatro itens, além desta introdução. $\mathrm{O}$ item 2 destaca os principais elementos teóricos que caracterizam a relação entre os sistemas financeiro e produtivo. O item 3 desenvolve o modelo propriamente dito. No item 4 são apresentados os resultados das simulações realizadas e finalmente, algumas considerações a título de conclusão são feitas no último item.

1 O termo é utilizado em Ruiz (2003) e se baseia na crítica de Tirole (1988, p. 100) à utilização de uma função CES pelos modelos tradicionais de concorrência monopolística: "The latter utility function [CES] treats all differentiated products in a symmetric way". Distingue-se assim, a presente abordagem, daquela encontrada nos modelos tradicionais a la Chamberlain, particularmente o modelo Dixit-Stiglitz (Dixit e Stiglitz, 1977).

2 Outros esforços, no sentido de se integrar os setores produtivo e financeiro em modelos agent-based, podem ser encontrados em Lima e Freitas (2007), Possas e Dweck (2004) e DelliGatti, Gallegati e Russo (2005). Particularmente, neste último, os autores reproduzem importantes fatos estilizados referentes à dinâmica industrial, tais como as leis de potência que regem a distribuição do tamanho das firmas. Mais especificamente, uma proposta de conciliação entre as teorias keynesianas e schumpeterianas a partir de modelos agent-based pode ser encontrada em dois trabalhos sequenciais, a saber: Dosi, Fagiolo e Roventini (2010) e Dosi et al. (2012) nos quais os autores defendem uma complementariedade entre políticas de incentivo a demanda e a inovação tecnológica. Para maiores detalhes sobre modelagem com agentes ver: Foley (2002), Holland e Miller (1991), Tesfatsion (2006) e Epstein (2006). 


\section{INCERTEZA E FORMAÇÃO DE EXPECTATIVAS EM UM MODELO FINANCEIRO-PRODUTIVO COM AGENTES HETEROGÊNEOS}

Agentes financeiros e produtivos compartilham o mesmo ambiente expectacional. Ao fornecer os recursos necessários ao investimento os primeiros devem crer que o fluxo de rendas futuras decorrentes da atividade produtiva será suficiente para cobrir os encargos dos débitos contraídos. No entanto, os resultados do investimento só podem ser conhecidos ex post. A qualidade relativa do produto é uma atribuição do consumidor - isto é, não pode ser conhecida a priori pelo produtor - e varia entre os diferentes bens e em função do conjunto de bens disponíveis no mercado. Ademais, os fluxos de produção, as variações nos preços individuais e a entrada e saída de firmas altera recorrentemente a quantidade demandada, de modo que as firmas não conhecem a sua curva de demanda com precisão suficiente para o alcance de um equilíbrio. No que interessa ao presente trabalho, tais características são consideradas suficientes para ilustrar a incerteza no seu sentido forte (Vercelli, 1991; Dequech, 1999) . $^{3}$

A diferenciação assimétrica e a variedade de tecnologias colocam ainda dificuldades quanto à determinação da demanda e à maximização do lucro pelas vias tradicionais ao implicar taxas marginais de substituição diferenciadas. Varian (1992, p. 1920) reconhece esse problema, o qual é também apontado por Tirole (1988, p. 100). A utilização de um mecanismo similar àquele proposto por Silverberg, Dosi e Orsenigo (1988) pode se constituir em uma forma adequada de se resolver, a partir das condições acima descritas, o problema da determinação da demanda. Entretanto, quando se assume que essa não é passível de ser conhecida ex ante, a produção deve ser definida de acordo com expectativas da demanda futura. A natureza não estacionária do ambiente considerado sugere a utilização de informações passadas (backward looking forecasting) processadas por meio de comportamentos rotineiros, particulares a cada firma, como forma de se inferir sobre o grau da variável em questão no período $t+1$. A esse respeito, Arthur (1994) propõe que é justamente a heterogeneidade das regras de tomada de decisão que possibilitam a evolução consistente de um sistema, ainda que sujeito a certa instabilidade.

Além dos riscos inerentes ao próprio mercado, a firma deverá lidar com a possibilidade de alteração do estado de expectativas dos agentes financeiros. De acordo com a formulação minskyana da instabilidade financeira (Minsky, 1975, 1982, 1986), o

\footnotetext{
Vercelli destaca a distinção entre risco (incerteza fraca) e incerteza (forte) feita por Knight. Nas palavras do autor, "risk refers to probability distributions based on reliable classification of possible events. Uncertainty refers to events whose probability distribution does not exist or is not soundly definable for lack of reliable classification criteria" (Vercelli, 1991, p. 72).
} 
incentivo ao investimento é maior quanto maior for o preço de demanda de um bem de capital em relação ao seu preço de oferta. ${ }^{4}$ Uma piora nas condições de financiamento impacta positivamente o preço de oferta, reduzindo os incentivos ao investimento. A consequente redução da demanda agregada deteriora as condições de solvência das firmas, empurrando o sistema para uma situação de fragilidade financeira. O processo ganha características cumulativas via elevação do spread bancário e racionamento de crédito. Uma crise financeira dá lugar, então, a uma crise na produção. $O$ resultado desse processo será a recomposição da robustez financeira por meio da exclusão do mercado de um grande número de firmas situadas nos regimes financeiros inferiores. A implicação elementar da Hipótese da Instabilidade Financeira (HIF) é de que o comportamento maximizador de lucro de firmas e bancos é, em sua natureza, um fator de instabilidade, gerando endogenamente crises financeiras periódicas com reflexos na economia real ${ }^{5}$.

\section{O MODELO}

\subsection{O LADO DA OFERTA: PRODUÇÃO E FORMAÇÃO DE PREÇOS}

Os mecanismos apresentados neste subitem e no próximo têm como base o trabalho de Ruiz (2003). As características gerais do setor produtivo são: (i) as firmas produzem produtos assimetricamente diferenciados, isto é, consumidores atribuem qualidades específicas a cada produto; e (ii) cada firma produz um único bem e o único insumo utilizado é o trabalho. O capital é entendido como capital monetário. A assimetria entre as firmas decorre do fato de que cada uma dessas possui uma combinação específica dos parâmetros tecnológicos $F$ (custo fixo), $T$ (coeficiente técnico de transformação) e $A$ (parâmetro de diferenciação de produtos), selecionados aleatoriamente a partir de uma

4 Em linhas gerais, segundo Keynes (1985), o preço de demanda é determinado pelo fluxo de rendimentos esperados ao longo da vida útil do investimento ajustado pelo grau de confiança - subjetivo e particular a cada agente - que é atribuído a essa estimativa. O retorno esperado é, basicamente, função da situação financeira do demandante e do seu poder de mercado que, como destacado por Minsky (1986), constitui um determinante essencial do fluxo de rendas que podem ser geradas por um ativo. O preço de oferta é influenciado basicamente pelos custos de reprodução do bem de capital, onde estão incluídos o patamar de salário e os custos financeiros.

5 A Hipótese da Instabilidade Financeira (HIF) tem sido frequentemente utilizada para analisar as turbulências que tem acometido o sistema financeiro internacional nos últimos anos. Nessa linha de investigação, Vercelli (2011) propõe uma definição precisa do chamado "momento Minsky", Davidson (2008) questiona se de fato a crise do subprime pode ser analisada nos termos da HIF e Dymski (2010) discute a eficácia dos mecanismos propostos por Minsky (intervenções fiscais feitas por um setor governamental suficientemente grande e a atuação do Banco Central como emprestador de última instância) para fazer frente à crise atual. 
distribuição normal. O conjunto das possibilidades tecnológicas corresponde, então, ao vetor de tecnologias do modelo. O grau de assimetria tecnológica é definido exogenamente, mediante a fixação do desvio-padrão das distribuições de cada parâmetro. A quantidade total ofertada pela firma $i(Q)$ em cada período $t$ é dada pela sua estrutura tecnológica (função de produção), pela quantidade de insumo utilizado $(L)$ - definida pelas expectativas de demanda - e pelos estoques $(V)$ eventualmente existentes, o que pode ser definido como:

$$
Q_{i, t}=T_{i}\left(L_{i, t}-F_{i}\right)+V_{i, t}
$$

Nota-se que, tal como proposto por Ruiz (2003, p. 38), F refere-se a um custo fixo, definido como uma quantidade mínima do fator trabalho necessária para se iniciar a produção. Isso significa que, se $F_{i}>L_{i t}$, a firma não possui a quantidade mínima de insumo requerida pela sua tecnologia, sendo então excluída do mercado.

A determinação da quantidade a ser produzida (produção desejada) em cada período levará em conta dois aspectos, a saber: (i) a demanda esperada $\left(Q^{e}\right)$, determinada por meio de expectativas formadas com base em observações passadas da sua demanda efetiva $(D)$; e (ii) os estoques $(V)$, que surgem quando $D<Q^{e}$. Assim, a produção desejada pela firma para o período corrente $\left(Q^{e}\right)$ será dada por:

$$
\begin{aligned}
& Q_{i, t}^{d}=\left(Q_{i, t}^{e}-V_{i, t}\right) \text { se } Q_{i, t}^{e}>V_{i, t} \\
& Q_{i, t}^{d}=0 \text { se } Q_{i, t}^{e} \leq V_{i, t}
\end{aligned}
$$

O único insumo utilizado na produção é o trabalho $(L)$, cujo volume necessário para a realização da quantidade $Q^{d}$ pode ser obtido rearranjando-se a função de produção da seguinte forma:

$$
L_{i, t}=\left[Q_{i, t}^{d}+\left(T_{i} F_{i}\right)\right] / T_{i}
$$

Considerando-se uma oferta de trabalho infinitamente elástica a uma taxa de salário fixa $(\bar{W})$, o custo da produção para a firma será igual a $\bar{W} L$. Para as firmas que já se encontram no mercado, os referidos custos poderão ser cobertos por fundos internos, que se referem a lucros acumulados $\left(A^{P}\right)$ ou, quando esses forem nulos ou insuficientes, por fundos externos na forma de financiamentos bancários $\left(K^{L}\right)$ - o caso específico do financiamento à entrada será oportunamente discutido no item 2.4. A demanda por financiamento no período corrente é definida em três situações distintas, a saber: (i) o volume dos estoques é inferior à demanda esperada e os lucros acumulados são insuficientes para cobrir os custos de produção; (ii) a demanda esperada é maior que o 
volume de estoques, porém os lucros acumulados são suficientes para realizar a produção desejada; e (iii) a expectativa de demanda é menor ou igual aos estoques acumulados. Para cada um dos casos a demanda por financiamento $\left(K^{L}\right)$ e o montante de capital para investimento no período $(K)$ são definidos, respectivamente, $c^{6}{ }^{6}$ :

(i) $K_{i, t}^{L}=\left(\bar{W} L_{i, t}-A_{i, t-1}^{P^{*}}\right)$ se $Q_{i, t}^{e}>V_{i, t}$ e $A_{i, t-1}^{P}<\bar{W} L_{i, t}$

$$
K_{i, t}=K_{i, t}^{L}+A_{i, t}^{P^{*}}
$$

(ii) $K_{i, t}^{L}=0$ se $Q_{i, t}^{e}>V_{i, t}$ e $A_{i, t-1}^{P} \geq \bar{W} L_{i, t}$

$$
K_{i, t}=A_{i, t}^{P^{*}}
$$

(iii) $K_{i, t}^{L}=0$ se $Q_{i, t}^{e} \leq V_{i, t}$

$$
K_{i, t}=0
$$

A determinação do preço segue uma regra de mark-up $(M k)$ sobre os custos unitários, de acordo com a seguinte equação:

$$
P_{i, t}=\frac{M k_{i, t}\left[\left(A_{i, t-1}^{D}+K_{i, t}^{L}\right)\left(1+r_{t}\right)+A_{i, t}^{P^{*}}\right]}{Q_{i, t}^{e}},
$$

onde $A_{i, t-1}^{D}$ é a dívida herdada do período anterior.

Na equação 7 o preço fixado visa a gerar uma receita esperada $\left(P Q^{e}\right)$ maior que os custos financeiros devidos no período e ainda a propiciar a remuneração do capital próprio. A firma que eventualmente não possua nenhum estoque de dívida, não contraia empréstimos e não apresente lucros acumulados no período corrente fixará o seu preço ao nível igual ao do período anterior $P_{i, t}=P_{i, t-1}{ }^{7}$.

6 O termo $A_{i, t}^{P^{*}}$ indica a parcela de $A_{i, t}^{P}$ que será usada para custear a produção. Por simplicidade, assume-se que recursos próprios quando não utilizados na produção permanecem ociosos, isto é, não têm rendimentos. Observa-se ainda que o total de crédito demandado possa ser maior que o montante de recursos de que o banco dispõe ou esteja disposto a ofertar. Nesse caso, um artifício simplificador é utilizado, aplicando-se um fator de redução, proporcional ao desequilíbrio do mercado, às demandas individuais de crédito de modo a ajustar, ex post, demanda e oferta de crédito.

7 Este artifício é uma simplificação. Não obstante, pode ser justificado pela ideia de satisficing (Simon, 1959). 
Por simplicidade o sistema bancário será representado por um único grande banco, de abrangência nacional. A taxa de juros de empréstimo $(r)$ cobrada por este corresponde à taxa básica $\left(i^{*}\right)$ acrescida do spread bancário $(z)$; este último, a ser definido no item 3.5. Formalmente, tem-se:

$$
r_{t}=\left(1+z_{t}\right) i^{*}
$$

\subsection{O LADO DA DEMANDA: COMPETITIVIDADE E MARKET-SHARE}

Modelos evolucionários têm se utilizado de uma forma bastante peculiar de determinação da demanda que tem como base um mecanismo proposto originalmente por Silverberg, Dosi e Orsenigo (1988). A essência desse é dada por uma relação circular estabelecida entre competitividade e market-share. Inicialmente, a competitividade $\left(C_{i}\right)$ pode ser descrita como uma função do preço, do market-share $\left(M_{i}\right)$ e das características específicas do produto $\left(A_{i}\right)$, o que é representado pela seguinte equação:

$$
\begin{aligned}
& C_{i, t}=\frac{1}{P_{i, t}\left(M_{i, t}^{A_{i}}\right)}, \text { onde } \frac{d C}{d P}<0 ; \quad \frac{d C}{d M}<0 ; \quad \frac{d C}{d A}>0, \\
& 0<M_{i, t}<1 \text { e } \sum M_{i, t}=1
\end{aligned}
$$

A equação 9 informa que a competitividade da firma $i$ no período $t$ varia inversamente ao seu preço e ao seu market-share e diretamente ao grau de diferenciação do produto $(A)$. Vale notar que, quanto mais elevado o parâmetro $A$, menos a competitividade depende do preço ou em outros termos, mais rígida é a curva de demanda individual ${ }^{8}$.

Por outro lado, o crescimento de $M$ em $t+1$ é determinado a partir de uma comparação entre a competitividade da firma e a competitividade média (ponderada pelos respectivos market-shares) da indústria $(\bar{C})$ no período $t$. Formalmente, a evolução de $M$, dada pela equação 10, é descrita como uma cadeia de Markov, especificada da seguinte forma9 :

$$
M_{i, t+1}=M_{i, t}\left[1+\lambda\left(\frac{C_{i, t}}{\bar{C}_{t}}-1\right)\right] ;
$$

\footnotetext{
8 Note que a elasticidade-preço da equação 9 é dada por $\varepsilon=-1 / P M^{A} C$.

9 Particularmente, a equação 10 refere-se a uma versão discreta da replicator dynamic equation, inicialmente desenvolvida para o estudo da seleção biológica como uma formalização do princípio evolucionário de sobrevivência dos mais aptos de Darwin (Silverberg, 1997, p. 3).
} 
onde

$$
\bar{C}_{t}=\sum_{i=1}^{n} C_{i, t} M_{i, t}
$$

Sendo $\lambda$, definido exogenamente, determinando a velocidade com que $M$ varia em função de mudanças no diferencial de competitividade. Observa-se uma relação circular estabelecida entre as equações 9 e 10, impondo um limite ao crescimento das firmas.

A demanda monetária da firma é, então, definida como uma parcela da renda disponível $\left(Y^{d}\right)$, proporcional ao seu market-share que, quando ponderada pelo preço praticado, define a demanda quantidade:

$$
D_{i}=M_{i}\left(Y_{t}^{d} / P_{i}\right)
$$

A renda agregada $(Y)$, por sua vez, é definida pela massa salarial repassada das firmas aos trabalhadores $(\bar{W} L)$, somada a uma eventual "poupança” $(S)$, da seguinte forma:

$$
Y_{t}=\sum_{i=1}^{n} W_{t} L_{i, t}+S_{i, t-1}
$$

Supõe-se, por simplificação, que toda renda é alocada para ao consumo, de modo que a variável $S$ deve, então, ser entendida como "renda não gasta", que se verifica para cada firma quando a quantidade demandada $\left(D_{i}\right)$ supera a quantidade ofertada $\left(Q_{i}\right)$. Nesse caso, a renda não gasta em um período é transferida para o período seguinte (postergação de gasto).

\subsection{REGIMES FINANCEIROS}

Uma vez determinados os níveis de oferta e de demanda, a heterogeneidade de firmas - tecnológica e expectacional - implicará que muitas dessas apresentarão excesso de oferta ou de demanda. Se $R$ é a receita obtida por cada firma no período, os cenários possíveis podem ser representados por:
i) se $D_{i, t}>Q_{i, t} \Rightarrow R_{i, t}=P_{i, t} Q_{i, t} ; \quad S_{i, t}=P_{i, t}\left(D_{i, t}-Q_{i, t}\right)$ e $V_{i, t}=0$;
ii) se $D_{i, t}<Q_{i, t} \Rightarrow R_{i, t}=P_{i, t} D_{i, t} ; \quad S_{i, t}=0$ e $V_{i, t}=\left(Q_{i, t}-D_{i, t}\right)$;
iii) se $D_{i, t}=Q_{i, t} \Rightarrow R_{i, t}=P_{i, t} D_{i, t} ; \quad S_{i, t}=0$ e $V_{i, t}=0$. 
Quando $D_{i}>Q_{i}$ (excesso de demanda), a firma não fornece a quantidade demandada pelos consumidores, os estoques serão $V=0$ e a poupança será $S>0$. Quando $D_{i}<Q_{i}$ (excesso de oferta), a firma fornece a quantidade demandada pelos consumidores, implicando $S=0$ e $V>0$.

Ao final do período a firma dispõe de uma receita $(R)$. Eventualmente, uma firma pode possuir recursos próprios (lucros acumulados) que não foram utilizados na produção $\left(A_{i, t}^{P}-A_{i, t}^{P^{*}}\right)$. Como esses, por hipótese, não têm rendimentos, os recursos totais de que a firma dispõe ao final de cada período produtivo $\left(R^{T}\right)$ são representados por:

$$
R_{i, t}^{T}=R_{i, t}+\left(A_{i, t}^{P}-A_{i, t}^{P^{*}}\right)
$$

Espera-se que esse montante seja suficiente para a quitação dos débitos do período $(E)$, os quais são expressos por:

$$
E_{i, t}=\left(1+r_{t}\right)\left(A_{i, t-1}^{D}+K_{i, t}^{L}\right)
$$

É importante observar que a equação 18 pode ser dividida em:

$$
\begin{aligned}
& J_{i, t}^{*}=r_{t}\left(A_{i, t-1}^{D}+K_{i, t}^{L}\right) \mathrm{e} ; \\
& A M_{i, t}^{*}=\left(A_{i, t-1}^{D}+K_{i, t}^{L}\right)
\end{aligned}
$$

Que correspondem, respectivamente, aos juros devidos e ao montante principal a ser amortizado.

A essa altura é possível introduzir a taxonomia de regimes financeiros proposta por Minsky (1986, p. 206). Do ponto de vista do setor financeiro o desejável é que todas as firmas obtenham recursos suficientes para a quitação de seus débitos, implicando uma posição Hedge. Entretanto, o que ocorre é que, diferenças em termos de formação de expectativas e capacitações tecnológicas farão emergir outros dois tipos de endividamento: o Especulativo, em que a firma consegue pagar os juros sem, entretanto, amortizar o principal; e o endividamento Ponzi, em que nem a amortização nem o pagamento dos juros são efetuados. Formalmente, tais possibilidades são expressas por:

$$
\begin{array}{ll}
R_{i, t}^{T} \geq E_{i, t} ; & \text { Hedge } \\
J_{i, t}^{*} \leq R_{i, t}^{T}<E_{i, t} ; & \text { Especulativo } \\
R_{i, t}^{T}<J_{i, t}^{*} . & \text { Ponzi }
\end{array}
$$


Quando uma firma não consegue pagar na totalidade os seus encargos financeiros, a quantia pendente é incorporada ao seu estoque de dívida. Como se observa pela equação 7, isso afetará positivamente o seu preço no período seguinte e, por conseguinte, a sua competitividade, de forma inversa. A acentuação desse processo poderá resultar na exclusão da firma do mercado a partir do momento em que não for atendida a condição $L_{i, t} \geq F_{i}$. Assume-se que, uma vez no mercado, existe uma tendência ao refinanciamento das firmas inadimplentes por parte dos bancos ${ }^{10}$.

\subsection{FINANCIAMENTO À ENTRADA E RACIONAMENTO DE CRÉDITO}

O resultado da interação entre oferta e demanda de crédito definirá o volume de financiamentos e, consequentemente, os novos investimentos do período. Uma vez solicitado o financiamento, o banco procurará estimar o risco do investimento, determinando se e em que condições o financiamento será efetivado. Propõe-se, assim, uma rotina de “avaliação de projetos", baseada em uma comparação entre uma estimativa de preço $\left(P^{\star}\right)$ a ser praticado caso a firma entre no mercado (um indicador da competitividade esperada), que é fornecida pelo demandante de crédito, e um preço limite estipulado pelo banco $\left(P^{B}\right)$, como critério para concessão ou não do financiamento. Assim, é estimada uma demanda esperada, que leva em conta as características tecnológicas do projeto e o grau de confiança do empreendedor. As primeiras são definidas no âmbito da função de produção e a segunda, dada a sua natureza subjetiva, é definida como um número aleatório $(\gamma)$, com distribuição uniforme e pertencente ao intervalo $(1, \mu)$. Para a realização da produção desejada $\left(Q^{*}\right)$ - que no ato da entrada equivale à demanda esperada - necessita-se de uma quantidade mínima de capital $\left(K^{\star}\right)$, dada por:

$$
K_{i}^{*}=\gamma_{i} F_{i} \bar{W}
$$

A quantidade de insumo desejada $\left(L^{*}\right)$ é então dada por:

$$
L_{i}^{*}=K_{i}^{*} / \bar{W}
$$

Substituindo $L^{*}$ na função de produção, tem-se:

$$
Q_{i}^{*}=T_{i}\left(L_{i}^{*}-F_{i}\right)
$$

\footnotetext{
${ }_{10}$ Bancos geralmente se empenham em estabelecer relações com seus clientes no intuito de reduzir a incerteza. Uma vez que constroem uma relação com um cliente, têm fortes incentivos para atender as demandas daquele cliente (Wray, 1992, p. 164).
} 
Uma vez estimada a demanda, o preço esperado (competitividade esperada) da firma é definido como ${ }^{11}$ :

$$
P_{i}^{*}=\frac{M k_{i} K_{i}^{*}\left(1+r_{t}\right)}{Q_{i}^{*}}
$$

O financiamento será concedido se $P_{i}^{*} \leq P_{t}^{B}$. Resta, portanto, especificar a forma como $P^{B}$ é determinado. Para isso, considere o seguinte indicador:

$$
h_{t}=\frac{\left(\sum_{i=1}^{n}\left(J_{i, t}-X_{i, t}^{F}\right)\right) / X_{t}^{C}}{B_{t} / X_{t}^{B}}
$$

O setor bancário poderá aplicar seus recursos em dois ativos distintos, a saber: crédito (baixa liquidez e alto retorno esperado) e títulos públicos (alta liquidez e baixo retorno esperado). Na equação $29 h$ representa uma comparação entre os rendimentos líquidos percentuais dos montantes $X^{C}$ e $X^{B}$ aplicados em cada um desses, respectivamente. O rendimento dos títulos é dado por $B$ (ver subitem 2.6). Do rendimento dos financiamentos, dado pelo somatório dos juros pagos, deve-se, entretanto, deduzir a perda de capital em que o banco incorre quando uma firma vai à falência; esta é representada por $X^{F}$ e se refere ao somatório do montante principal não amortizado das firmas excluídas. Em uma situação de robustez financeira nota-se que $h>1$ - mais precisamente, será igual à razão entre a taxa de juros de empréstimo e a taxa básica de juros da economia. Poderá, entretanto, assumir valores negativos, em função da falência de firmas, implicando perda de capital para o banco.

No que se refere à postura do banco quanto ao financiamento de novas firmas, o valor do referido indicador terá especial importância para o estabelecimento de

11 O papel das expectativas na entrada e a sua relação com o preço potencial podem ser explicitados reescrevendo-se a equação 27. Substituindo nessa, as equações 26, 25 e 24, respectivamente, obtém-se: $P_{i}^{*}=M k_{i}\left(\frac{\gamma_{i}}{\gamma_{i}-1}\right)\left(\frac{\left(1+r_{t}\right) W_{t}}{T_{i}}\right)$

Nota-se que o primeiro termo descreve uma hipérbole retangular com limite igual a 1 quando $\gamma$ tende a infinito, o que enseja duas observações relevantes, a saber: i) valores mais elevados desse parâmetro estão associados a expectativas mais otimistas na entrada; ii) o aumento de $\gamma$ também implica um alto endividamento, o que pode ser decisivo para a permanência da firma no mercado caso a demanda se revele abaixo do esperado. Essa última observação justifica a delimitação do parâmetro dentro de um intervalo (ver equação 24) consistente com comportamentos que podem ser considerados racionais. Em outros termos, valores elevados do mesmo aumentam a chance de obtenção do financiamento bancário, porém expõe a firma a um maior risco de default, sendo que o oposto também é válido. 
comportamentos rotineiros. As implicações de $h$ sobre a disposição em financiar entradas, medida por $P^{B}$, podem ser assim representadas:

$$
P_{t}^{B}=\left\{\begin{array}{l}
\infty \text { se } h_{t-1}>1 ; \\
\bar{P}_{t-1} \text { se } 0<h_{t-1}<0 \text { ou } P_{t-1}^{B}<\bar{P}_{t-1} ; \\
\frac{\bar{P}_{t-1}}{\sigma\left(h_{t-1}^{t-k}\right)} \text { se } h_{t-1}<0 \text { ou } P_{t-1}^{B}<\bar{P}_{t-1} .
\end{array}\right.
$$

Especificamente, a equação 30 define $P^{B}$ como uma função descontínua de $h$, em que o nível médio de preços das firmas hedge da economia $(\bar{P})$ é tomado como parâmetro. Essa forma funcional implica quebras estruturais na dinâmica do sistema, ditadas por mudanças comportamentais por parte do setor bancário quando um de seus indicadores-chave $(h)$ atinge níveis críticos. Dado que a condição de entrada é definida por $P_{i}^{*} \leq P_{t}^{B}$, na equação 30 a $P^{B}$ assume valor infinito para representar o caso de ausência de restrição na concessão de financiamentos. Na equação $30 \mathrm{~b}$ o banco torna-se mais criterioso e só se dispõe a financiar caso o preço potencial apresentado pela firma seja pelo menos igual ao preço médio das firmas situadas em regime financeiro hedge $(\bar{P})$. Pela equação 30c pode-se chegar à restrição de crédito se a perda de capital bancário se revelar suficientemente elevada. Observa-se que o denominador dessa última equação refere-se ao desvio-padrão da variável $h$ - tomado aqui como um indicador de estabilidade/instabilidade - calculado no intervalo $[t-1, t-\mathrm{k}]$, onde $k$ é um número fixo de observações passadas de $h$. De fato, $k$ é um parâmetro comportamental; quanto mais elevado, maior será a memória do banco com respeito às fases de estabilidade/instabilidade, com implicações sobre a sua postura na concessão de empréstimos.

\subsection{DETERMINAÇÃO DO SPREAD BANCÁRIO}

Além do indicador de desempenho dos ativos fornecido pela equação 29, outro aspecto igualmente importante diz respeito à qualidade da carteira de ativos, particularmente no que se refere à taxa de inadimplência sobre as operações de crédito, que pode ser considerada como uma medida do grau de fragilidade financeira percebida. Essa é denominada por $H$ e pode ser expressa da seguinte forma:

$$
H_{t}=\sum_{i=1}^{n} \frac{\left(J_{i, t}^{*}+A M_{i, t}^{*}\right)-\left(J_{i, t}+A M_{i, t}\right)}{\left(J_{i, t}^{*}+A M_{i, t}^{*}\right)}
$$


Os termos $\left(J_{i, t}^{*}+A M_{i, t}^{*}\right)$ e $\left(J_{i, t}+A M_{i, t}\right)$ representam, respectivamente, o total de pagamentos que deveriam ser realizados e os pagamentos efetivos. O spread bancário $(z)$ pode, então, ser especificado como uma função da taxa de inadimplência, da seguinte forma:

$$
z_{t}=\alpha H_{t-1}+(1-\alpha) H_{t} ; 0<\alpha<1
$$

A equação 32 implica uma defasagem de $z$ em relação à $H$, que aumenta quanto mais próximo de 1 for o valor do parâmetro $\alpha$. Assim, quando a fragilidade percebida cai, o spread reage com atraso, representando uma tentativa de recuperação do capital perdido com o ônus sobre as firmas adimplentes. Da mesma forma, a defasagem de $z$, quando $H$ se eleva, tenta captar o comportamento especulativo inerente ao setor bancário. Uma vez definido o spread, a taxa de juros de empréstimo pode ser obtida por meio da equação 8 .

\subsection{POLÍTICA ECONÔMICA E RENDA DISPONÍVEL}

Na construção do modelo básico será considerada uma política de taxa de juros fixa e orçamento equilibrado, de modo que as políticas fiscal e monetária deverão se ajustar para atingir essa meta. Essa opção pode ser modelada definindo-se a tributação como sendo realizada diretamente sobre a renda, cuja alíquota $(\beta)$ varia de modo a garantir a igualdade entre arrecadação e remuneração dos títulos, da seguinte forma:

$$
\beta_{t}=\frac{\left(i^{*}\right) X_{t}^{B}}{Y_{t}}
$$

Consequentemente, a renda disponível $\left(Y^{d}\right)$ e o volume de impostos arrecadados (B) - este último, correspondente ao rendimento dos títulos - são definidos, respectivamente, por:

$$
\begin{aligned}
& Y_{t}^{d}=\left(1-\beta_{t}\right) Y_{t}, \mathrm{e} \\
& B_{t}=\beta_{t} Y_{t}
\end{aligned}
$$

Como pode ser observado na equação 33, a alíquota tributária se altera a cada período, de modo a manter o orçamento público em equilíbrio. Dessa forma, a política econômica é endogeneizada como uma função das decisões do sistema financeiro sobre o volume das aplicações em títulos a cada período. 


\subsection{RESULTADO OPERACIONAL DO SETOR BANCÁRIO}

Ao final de cada período $t$ o capital disponível do banco para aplicações em $t+1(X)$ consistirá dos resultados obtidos em suas operações de crédito e das aplicações em títulos públicos.

$$
X_{t}=\left[X_{t}^{B}+B_{t}+\sum_{i=1}^{n}\left(J_{i, t}+A M_{i, t}\right)\right]
$$

Uma vez definido $X$, o ciclo se reinicia: as firmas demandarão crédito e o banco ofertará sob condições determinadas pela sua percepção de fragilidade financeira no momento em questão. Como medida preventiva, um volume mínimo de recursos $\left(X^{B}\right)$, definido como um percentual fixo $\varphi$ de $X_{t-1}$, é aplicado em títulos (equação 37). O restante é direcionado aos financiamentos ao setor produtivo.

$$
X_{t}^{B}=\varphi X_{t-1}
$$

Caso o montante destinado aos financiamentos seja menor que a demanda total, cada firma receberá uma quantia menor que a demandada, proporcional à diferença entre demanda e oferta totais de crédito. Caso seja maior, o resíduo é direcionado à aplicação em títulos, somando-se ao montante inicialmente definido pela equação 37. Note que a segunda possibilidade pode ocorrer, particularmente, na hipótese de racionamento de crédito.

\section{EVOLUÇÃO DO SISTEMA}

O presente modelo assume que firmas têm diferentes produtos, tecnologias e processos de formação de expectativas. A alocação assimétrica da renda entre os vários produtos depende de suas qualidades $(A)$ e de seus preços. Esses últimos, por sua vez, dependem das respectivas tecnologias de processo $\left(T_{i}\right.$ e $\left.F_{i}\right)$, das condições de financiamento implícitas na taxa de juros de empréstimo e do padrão de endividamento. A assimetria tecnológica é gerada à medida que cada firma possui uma combinação específica de $T$, $F$ e $A$. Nesse caso, cada variável em questão deve pertencer a um conjunto de números aleatórios normalmente distribuídos definidos por:

$$
0 \leq A_{i} \leq 1 ; \quad 0<T_{i} \leq 1 ; \quad 0 \leq F_{i} \leq 10 .
$$


O nível de assimetria é controlado exogenamente e é definido como o grau de dispersão em torno das médias das referidas variáveis. Quando a variância é zero, as firmas são homogêneas.

A determinação da demanda esperada ocorre de forma diferenciada entre as firmas a partir da observação das realizações passadas da quantidade demandada. Não se objetiva aqui avaliar a eficácia intertemporal dos processos individuais de formação de expectativas, mas analisar as implicações da heterogeneidade expectacional sobre a dinâmica do modelo ${ }^{12}$. A Tabela 1 apresenta oito regras distintas, a partir das quais o nível esperado de procura para o período corrente é definido.

Tabela 1 - Conjunto de regras decisórias para a determinação da demanda esperada

\begin{tabular}{l|l}
\hline Regra 1 & Média aritmética simples dos últimos 10 períodos \\
\hline Regra 2 & Máximo valor observado nos últimos 10 períodos \\
\hline Regra 3 & Mínimo valor observado nos últimos 10 períodos \\
\hline Regra 4 & Mediana dos últimos 10 períodos \\
\hline Regra 5 & Valor observado no período imediatamente anterior \\
\hline Regra 6 & Média aritmética simples dos últimos 5 períodos \\
\hline Regra 7 & Máximo valor observado nos últimos 5 períodos \\
\hline Regra 8 & Mínimo valor observado nos últimos 5 períodos \\
\hline
\end{tabular}

Fonte: Elaboração própria.

Dois casos são analisados, a saber: no primeiro, a regra que cada firma seguirá é definida aleatoriamente no ato da sua entrada e permanece fixa até o fim da simulação; o segundo caso introduz uma flexibilidade aos processos decisórios, no sentido de que as firmas podem mudar de estratégia caso julguem insatisfatório o resultado obtido no período de produção corrente. Vale notar que tais regras conferem a cada unidade produtiva distintos graus de otimismo/pessimismo, os quais afetarão o seu desempenho em diferentes fases do processo evolutivo. Por exemplo, uma firma que tem expectativas de demanda determinadas pela regra (2) é naturalmente mais otimista que aquelas que se guiam pela regra (3) ou mesmo pela regra (7).

No exercício que se segue é simulado o modelo básico, com parâmetros e condições iniciais definidos na Tabela 2. Posteriormente, algumas possibilidades serão exploradas, a partir de variações na parametrização inicial. Cabe ressaltar que pesquisas empíricas com vistas à calibragem do modelo constituem uma etapa posterior da presente investigação,

\footnotetext{
12 Essa metodologia se baseia nas proposições de Arthur (1994), apresentadas em seu modelo El Farol Bar.
} 
de modo que, por ora, serão utilizados parâmetros considerados plausíveis. O software utilizado é o Netlogo 3.1.5 (Wilensky, 1999). Os procedimentos da programação computacional encontram-se disponibilizados em Paula (2009).

Tabela 2 - Parâmetros e condições iniciais do modelo

\begin{tabular}{|c|c|c|c|c|c|}
\hline \multicolumn{3}{|c|}{ Parâmetros } & \multicolumn{3}{|c|}{ Condições Iniciais } \\
\hline & Grau de heterogeneidade & 0,60 (desvio-padrão) & & $\mathrm{N}^{\circ}$ inicial de firmas no mercado & 100 \\
\hline$A$ & Diferenciação de produto & 0,5 (média) & $M_{i}$ & Market-share & $1 / 100$ \\
\hline$T$ & Coeficiente de transformação & 0,5 (média) & $C_{i}$ & Competitividade & 1 \\
\hline$F$ & Custo fixo & 1,0 (média) & $r$ & Taxa de juros de empréstimo & 0,1 \\
\hline$W$ & Salário & 1 & $X$ & Volume de capital do banco & 1.000 \\
\hline$M k$ & Mark-up & 1,2 & & & \\
\hline$i^{*}$ & Taxa básica de juros & 0,01 & & & \\
\hline$\varphi$ & Aplicação mínima em títulos (\%) & 0,1 & & & \\
\hline$\lambda$ & Velocidade de ajustamento de $M$ & 0,1 & & & \\
\hline$\alpha$ & Coeficiente da equação 32 & 0,99 & & & \\
\hline$k$ & Memória do setor bancário & 20 & & & \\
\hline$\gamma$ & Indicador de expectativas & $(1,10]$ & & & \\
\hline
\end{tabular}

Fonte: Elaboração própria.

\subsection{POLÍTICA ECONÔMICA ACOMODATÍCIA E RACIONAMENTO DE CRÉDITO}

A partir dos valores listados na Tabela 2 a simulação foi realizada para 500 períodos. Os principais resultados são apresentados e discutidos a partir de alguns gráficos selecionados. Os Gráficos 1 e 2 fornecem uma visão geral da evolução do sistema.

Inicialmente, cabe ressaltar que não há crescimento econômico, o que permite que as flutuações cíclicas sejam analisadas sem a influência de uma tendência em longo prazo. A instabilidade é, então, avaliada em termos da distribuição dos recursos totais da economia entre os setores produtivo e financeiro. As flutuações da renda têm como limite superior um produto potencial fixo; nas proximidades desse a maior parte dos recursos da economia se encontra no setor produtivo. Um movimento oposto ocorre nos períodos de crise, em função de um aumento da preferência pela liquidez de empresas e bancos. Como se pode observar no Gráfico 1, o comportamento da renda é caracterizado por flutuações de diferentes intensidades. 
Gráfico 1 - Evolução da renda agregada

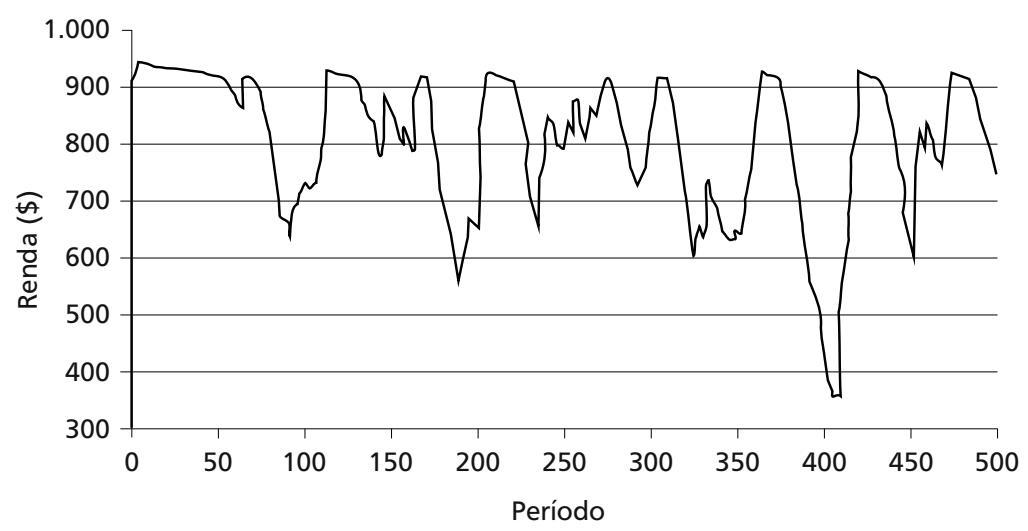

Fonte: Elaboração própria com base nos dados da simulação.

Gráfico 2 - Evolução do número de firmas

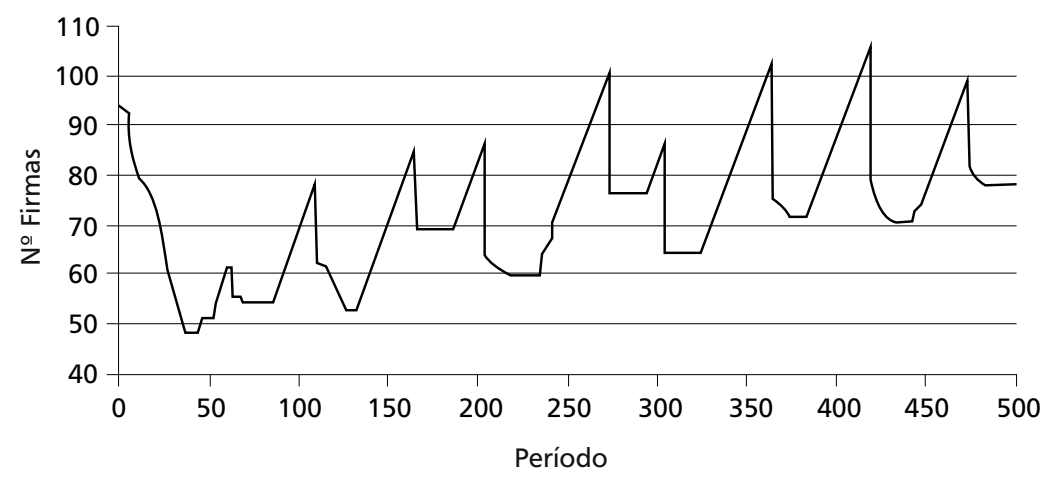

Fonte: Elaboração própria com base nos dados da simulação.

No Gráfico 2 observa-se que o número de firmas em operação se eleva continuamente em determinados períodos e cai de forma abrupta em seguida. Quando confrontados com o Gráfico 1 os movimentos ascendentes correspondem aos períodos de elevação do nível de renda, o que propicia a entrada bem sucedida de novas firmas. Por outro lado, a falência em massa se associa a fortes quedas do nível de renda. Nota-se, ainda no Gráfico 2 que, imediatamente após os períodos de falência, o gráfico geralmente apresenta um comportamento estável, representado por uma linha horizontal. A estabilidade do número de firmas nessa fase se explica tanto pelo grau de robustez financeira, característico das empresas remanescentes, quanto pelo racionamento de crédito que restringe a entrada de novas firmas imediatamente após a crise. 
Uma análise mais detalhada pode ser realizada mediante a observação do comportamento de outras variáveis do modelo no decorrer de um ciclo específico, por exemplo, aquele que ocorre em torno do período 400.

Gráfico 3 - Distribuição das firmas entre os regimes financeiros (\%) (período: 370-450)

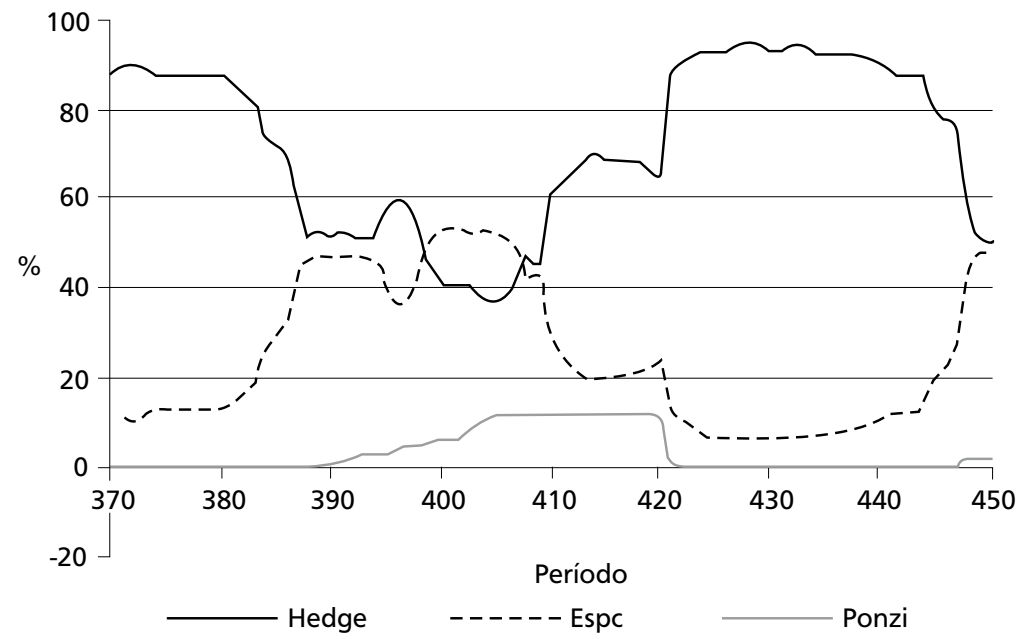

Fonte: Elaboração própria com base nos dados da simulação.

Gráfico 4 - Alocação dos recursos financeiros (período: 370-450)

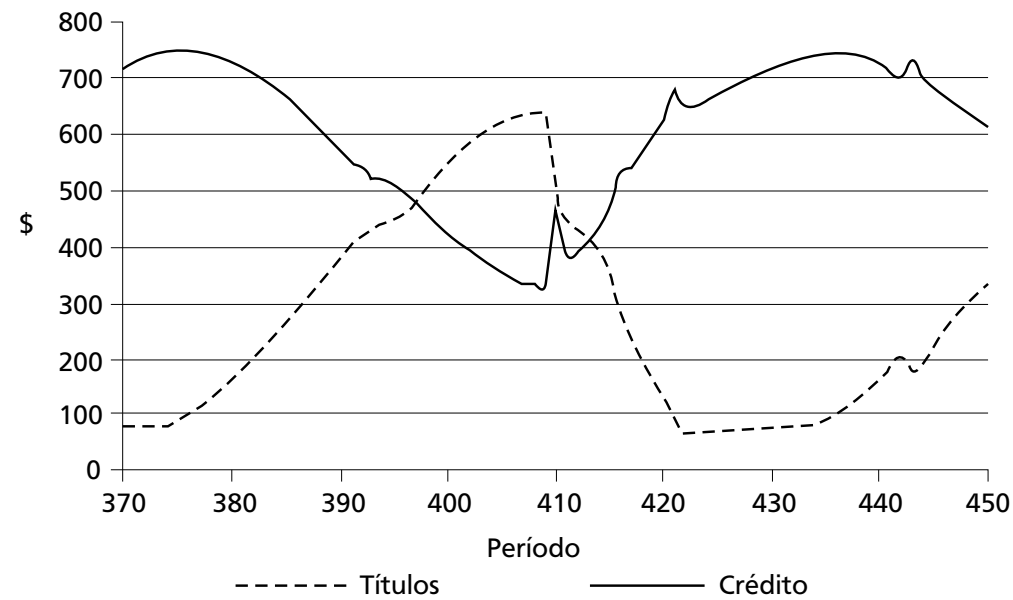

Fonte: Elaboração própria com base nos dados da simulação. 
Gráfico 5 - Evolução do spread bancário (período: 370-450)

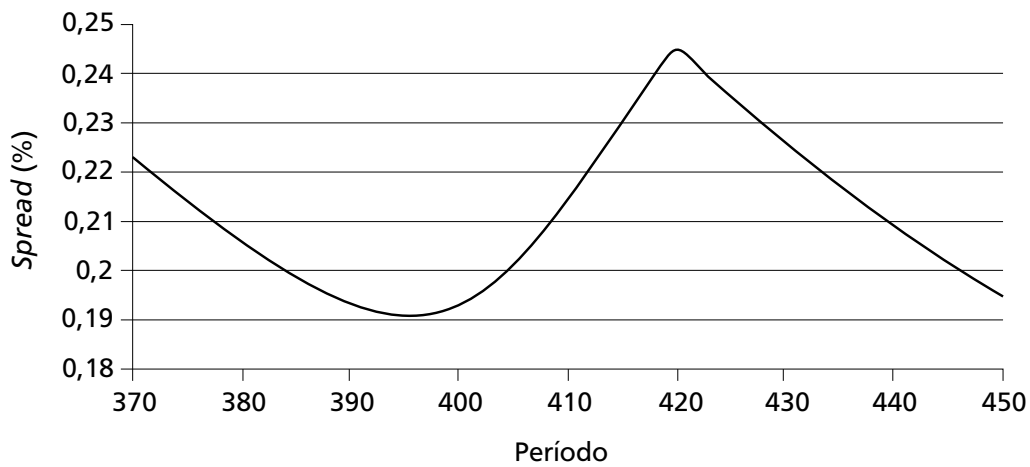

Fonte: Elaboração própria com base nos dados da simulação.

Gráfico 6 - Variação (\%) do nível de preços (período: 370-450)

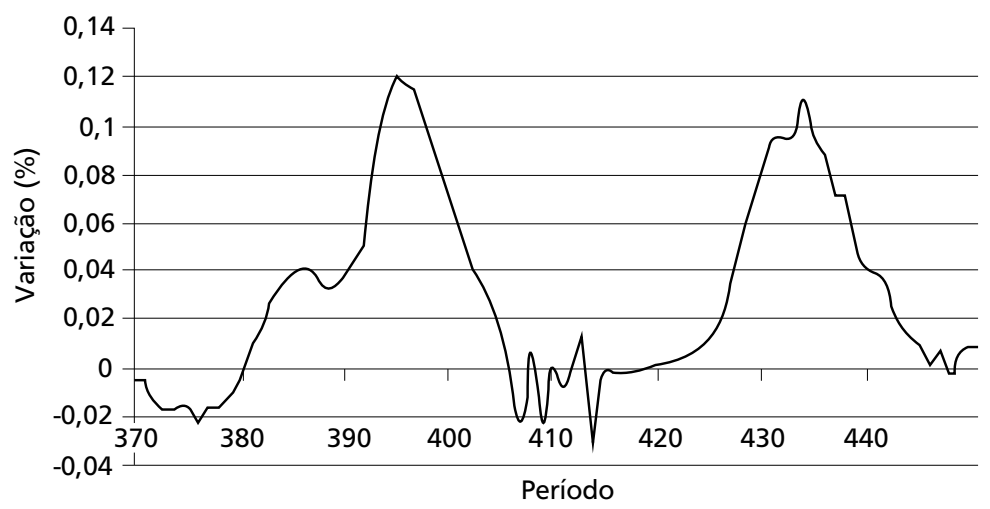

Fonte: Elaboração própria com base nos dados da simulação.

As bases para a emergência da crise começam a se estabelecer justamente quando o sistema atinge o seu maior grau de solidez financeira, o que se verifica por volta de $t=380$. Note que, a partir desse período, a fragilização financeira se eleva, com o aumento da proporção de firmas especulativas na economia (Gráfico 3). Nos primeiros momentos desse processo $(t=380$ a $t=395)$ a disposição do banco em ofertar crédito ainda é elevada, entretanto, as expectativas de demanda por parte das firmas começam a se deteriorar em função da não realização de lucros esperados, com consequente redução da demanda de crédito pelas firmas em operação, implicando em uma queda contínua, no referido período, do volume total emprestado (Gráfico 4). A deterioração do balancete bancário, em função da crescente inadimplência, reverte a tendência de queda do spread, que começa a se elevar em $t=395$ (Gráfico 5), impulsionando as firmas mais vulneráveis para o regime financeiro Ponzi (Gráfico 3). Como os preços são 
fixados de modo a cobrir os custos de produção, que incluem os custos financeiros, o endividamento crescente implica na elevação dos níveis de preço no período (Gráfico 6). Note que o período de alta inflação coincide com aquele em que a presença de firmas nos regimes especulativo e Ponzi é elevada (Gráficos 6 e 3, respectivamente).

$\mathrm{O}$ auge da crise ocorre em $t=409$, quando a renda atinge o seu nível mínimo. A renda disponível em cada período é determinada pela massa salarial e pela renda não gasta do período anterior, deduzindo-se a tributação. Dessa forma, o baixo nível de renda é explicado pelo reduzido montante de salários pagos - já que esta fase é caracterizada pela exclusão de um número significativo de firmas (Gráfico 2) - e pela consequente queda do nível de poupança. Por último, nesse ponto a arrecadação tributária atinge o seu pico, basicamente em função dos custos da política de taxa de juros fixa (estabelecida como hipótese), que força o governo a atender o aumento da demanda por liquidez do setor bancário observado no Gráfico 4.

O momento crítico do ciclo, que marca a transição da fase de fragilidade para a de robustez financeira, é caracterizado pela exclusão de um número significativo de firmas, que ocorre a partir de $t=420$. Cabe notar, no entanto, que o período de recuperação da renda começa antes desse ponto crítico; observe que a reversão de tendência do crédito e da renda tem início por volta de $t=410$. Isso ocorre devido ao fato de que, no período que antecede o ponto de exclusão em massa, a presença de firmas em regime especulativo e Ponzi é relativamente elevada. Tais firmas operam com expectativas de demanda tão reduzidas que no seu conjunto detém pouca parcela de mercado. Assim, há um espaço que é aproveitado pelas firmas mais eficientes, cujas expectativas são otimistas, conduzindo a um aumento da demanda de crédito, do investimento e da renda.

As empresas que têm poder de mercado (em função das características de seu produto) são as que mais sobrevivem em tempos de crise; isso por que a baixa elasticidade-preço da demanda implica que o impacto negativo sobre as receitas seja relativamente menor quando os preços estão se elevando (Gráfico 6). Este fato pode ser comprovado quando tomamos a média do parâmetro $A$ das empresas em operação como uma proxy da elasticidade ${ }^{13}$. No período que antecede a crise, isto é, quando o número de empresas na economia atinge o seu máximo $(t=420)$, o valor médio de $A$ é de 0,7209 , enquanto após a fase de exclusão $(t=442) A$ médio é igual a 0,8336 . Análise similar pode ser feita com relação ao parâmetro referente ao custo fixo $(F)$, cujo valor médio diminui de 0,848 para 0,719 entre os referidos períodos. Isso se explica pelo fato de que as firmas que mais sentem a queda na demanda são aquelas com elevadas economias de escala, as quais, depois de excluídas, reduzem o valor médio do referido parâmetro.

\footnotetext{
${ }^{13}$ Como já observado, a elasticidade-preço da equação 9 é dada por $\varepsilon=-1 / P M^{A} C$; nota-se que, quanto mais elevado o valor de $A$, mais rígida é a curva de demanda individual, implicando que a competitividade se reduz relativamente menos em função de uma dada elevação no preço individual.
} 


\subsection{PREFERÊNCIA PELA LIQUIDEZ DO SETOR BANCÁRIO E OFERTA DE CRÉDITO}

Como exposto no item 3.4, o parâmetro $k$ se relaciona com o tempo necessário para que as atividades de financiamento deixem de ser influenciadas pela instabilidade sistêmica. Mais especificamente, elevados valores deste parâmetro associam-se a uma postura mais defensiva na concessão de crédito. Neste exercício utiliza-se a mesma parametrização anterior com diferentes valores de $k$. A Tabela 3 apresenta algumas estatísticas básicas a partir de quatro cenários possíveis.

É possível observar a partir da Tabela 3 que o grau de instabilidade, medido pelo coeficiente de variação e pelo desvio-padrão $(\sigma)$, é maior quando $k$ se situa no seu valor máximo $(k=40)$. Das sete variáveis analisadas, apenas a primeira (número de firmas em operação) não apresentou essa característica. Ao mesmo tempo, quatro variáveis, dentre as sete selecionadas, apresentaram os menores indicadores de variabilidade quando $k=5$. No que diz respeito às médias, os menores valores para as variáveis "número de firmas", "renda" e "volume de crédito" são observados em $k=40$, o que se mostra consonante com situações em que o rigor para a concessão de financiamentos é elevado. Ainda nesse contexto, é possível notar que o sistema opera sob um nível de preços relativamente alto, o que constitui um reflexo tanto dos custos financeiros elevados - note que o spread bancário médio é também o mais elevado entre os casos simulados - quanto da baixa expectativa de demanda por parte das firmas (ver equação 7). Ainda com respeito ao spread, cabe notar que níveis médios elevados aumentam a velocidade com que o sistema se dirige à fragilização financeira. Isto pode ser notado pelo fato de que em $k=40$, onde o spread é em média o mais elevado, a presença (\%) de firmas hedge é a menor entre os casos simulados.

Tabela 3 - Estatísticas básicas do modelo

\begin{tabular}{|c|c|c|c|c|c|c|c|c|}
\hline & & $\mathrm{N}^{\circ}$ Firmas & Renda & $\begin{array}{l}\text { Nível de } \\
\text { Preços }\end{array}$ & Vol. Crédito & Spread & $\begin{array}{c}\text { Firmas } \\
\text { Hedge (\%) }\end{array}$ & $h$ \\
\hline \multirow{3}{*}{$k=40$} & Média & 64.244 & 675.773 & 4.980 & 552.099 & 0,243 & 67.936 & $-0,094$ \\
\hline & $\sigma$ & 11.619 & 214.704 & 5.958 & 151.233 & 0,087 & 17.295 & 12.570 \\
\hline & Coef. Var. & 0,181 & 0,318 & 1.196 & 0,274 & 0,357 & 0,255 & -133.857 \\
\hline \multirow{3}{*}{$k=20$} & Média & 83.432 & 797.781 & 3.689 & 657.858 & 0,165 & 78.332 & $-0,234$ \\
\hline & $\sigma$ & 15.671 & 122.396 & 1.999 & 82.285 & 0,053 & 11.741 & 9.837 \\
\hline & Coef. Var. & 0,188 & 0,153 & 0,542 & 0,125 & 0,321 & 0,150 & -41.985 \\
\hline \multirow{3}{*}{$k=10$} & Média & 86.660 & 827.388 & 2.939 & 670,289 & 0,148 & 80.589 & $-0,226$ \\
\hline & $\sigma$ & 15.530 & 121.509 & 2.410 & 85.964 & 0,051 & 13.163 & 10.069 \\
\hline & Coef. Var. & 0,179 & 0,147 & 0,820 & 0,128 & 0,342 & 0,163 & -44.509 \\
\hline \multirow{3}{*}{$k=5$} & Média & 92.257 & 839.602 & 2.696 & 672.689 & 0,127 & 80.980 & $-0,248$ \\
\hline & $\sigma$ & 16.387 & 120.831 & 1.563 & 85.410 & 0,040 & 14.171 & 9.287 \\
\hline & Coef. Var. & 0,178 & 0,144 & 0,580 & 0,127 & 0,316 & 0,175 & -37.380 \\
\hline
\end{tabular}

Fonte: Elaboração própria com base nos dados da simulação. 
De modo geral, a volatilidade tende a ser baixa quando $k$ é baixo e vice-versa. Entretanto, quando se observa a variável relacionada com o desempenho operacional do sistema bancário $(h)$, nota-se que o seu menor valor médio (em termos absolutos) é verificado quando $k=40$, sendo que o mesmo se eleva quando $k$ se reduz. A partir da definição de $h$ (equação 29), é possível inferir que as possibilidades de perda de capital tendem a ser menores quando $k$ é alto. Em outros termos, o racionamento de crédito melhora o desempenho do banco, constituindo, portanto, um comportamento racional em ambientes incertos, ainda que, notadamente, para o sistema como um todo seja um fator de instabilidade.

Uma interpretação possível é a de que valores de $k$ relativamente baixos estejam associados a ambientes em que a concorrência bancária é elevada; isso porque oportunidades de ganhos com a concessão de crédito podem ser aproveitadas por concorrentes, caso um banco específico insista em recorrer ao racionamento por períodos relativamente longos. De modo oposto, valores elevados de $k$ parecem caracterizar sistemas em que a concentração é elevada uma vez que, como o período de racionamento se verifica geralmente no auge e nos primeiros instantes após a crise, o qual se caracteriza pela robustez financeira, a recomposição de receitas via elevação do spread pode se revelar uma estratégia bastante vantajosa e se estender a períodos consideravelmente longos em função de uma ameaça relativamente reduzida por parte da concorrência. Em suma, o modelo sugere que sistemas financeiros com elevado grau de competição - a qual, geralmente, conduz a uma maior agressividade por parte dos agentes bancários, relacionando-se, portanto, com um menor valor de $k$ - tendem a recorrer com menos frequência ao racionamento de crédito, contribuindo para um maior grau de estabilidade sistêmica. De modo oposto, em sistemas financeiros concentrados, o racionamento é adotado com maior frequência, elevando o grau de instabilidade.

\subsection{VARIAÇÕES NA TAXA BÁSICA DE JUROS}

Uma análise similar a anterior pode ser feita em relação à taxa básica de juros. Embora o modelo não incorpore regras de política monetária, é possível inferir sobre os efeitos da fixação dos juros básicos em patamares distintos. A análise que se segue compara os resultados encontrados na simulação 4.1, em que $i^{*}=1 \%$, com aqueles obtidos em outros dois exercícios, nos quais $i^{*}=0,8 \%$ e $i^{*}=1,2 \%$. Os indicadores obtidos são apresentados na Tabela 4 , a seguir. 
Tabela 4 - Estatísticas do modelo em três cenários possíveis de taxa básica de juros

\begin{tabular}{c|c|c|c|c|c|c|c|c}
\hline & & No Firmas & Renda & $\begin{array}{c}\text { Nível de } \\
\text { Preços }\end{array}$ & Vol. Crédito & Spread & $\begin{array}{c}\text { Firmas } \\
\text { Hedge (\%) }\end{array}$ & $\boldsymbol{h}$ \\
\hline \multirow{2}{*}{$i^{*}=0,8 \%$} & Média & 81.654 & 838.876 & 2.579 & 662.406 & 0,123 & 83.314 & $-0,278$ \\
\cline { 2 - 9 } & $\sigma$ & 16.391 & 111.561 & 1.528 & 84.923 & 0,039 & 11.824 & 10.194 \\
\cline { 2 - 9 } & Coef. Var. & 0,201 & 0,133 & 0,592 & 0,128 & 0,315 & 0,142 & -36.661 \\
\hline \multirow{2}{*}{$i^{*}=1,0 \%$} & Média & 83.432 & 797.781 & 3.689 & 657.858 & 0,165 & 78.332 & $-0,234$ \\
\cline { 2 - 9 } & $\sigma$ & 15.671 & 122.396 & 1.999 & 82.285 & 0,053 & 11.741 & 9.837 \\
\hline & Coef. Var. & 0,188 & 0,153 & 0,542 & 0,125 & 0,321 & 0,150 & -41.985 \\
\hline \multirow{2}{*}{$i^{*}=1,2 \%$} & Média & 81.154 & 707.772 & 4.637 & 567.587 & 0,237 & 70.828 & $-0,177$ \\
\cline { 2 - 10 } & $\sigma$ & 13.529 & 211.746 & 4.461 & 148.287 & 0,076 & 18.612 & 13.101 \\
\cline { 2 - 9 } & Coef. Var. & 0,167 & 0,299 & 0,962 & 0,261 & 0,321 & 0,263 & -74.119 \\
\hline
\end{tabular}

Fonte: Elaboração própria com base nos dados da simulação.

A partir da Tabela 4, nota-se que em média a renda e o crédito se mostraram relativamente mais baixos quando a taxa básica de juros é mais alta $\left(i^{*}=1,2 \%\right)$. Nesse cenário, a baixa disponibilidade de crédito dificulta a entrada de firmas. Consequentemente, a diversidade produtiva na economia será menor, de modo que um número reduzido de firmas, com capacitação tecnológica relativamente mais elevada, tenderá a permanecer em atividade. A esse respeito, observa-se que tanto a média quanto a volatilidade do número de firmas em operação se mostraram menores. De modo geral, entretanto, nota-se uma maior instabilidade sistêmica: todos os demais indicadores de volatilidade se mostraram mais elevados quando $i^{\star}=1,2 \%$. Esse é um resultado esperado, já que encargos financeiros mais elevados aceleram o processo de fragilização financeira das unidades produtivas, induzindo os agentes do setor bancário a adotarem com maior frequência posturas defensivas na concessão de crédito. Como destacado anteriormente, fragilização financeira no setor produtivo e posturas defensivas no setor bancário constituem os pilares de um processo de causação mútua que se autorreforça, gerando instabilidade.

Não obstante - e, de forma aparentemente contraditória - o nível médio de preços se revelou diretamente relacionado com a taxa de juros. $\mathrm{O}$ fato de o modelo não incorporar um mecanismo de reajuste do mark-up, de modo que as firmas pudessem aumentar a sua lucratividade nos momentos em que a demanda se eleva (cenário de juros baixos), pode explicar tal comportamento. Ao mesmo tempo, o alto nível de preços quando os juros são altos se explica pelo repasse aos consumidores do elevado custo financeiro, imposto tanto pelo patamar elevado da taxa básica quanto pelo spread bancário, cuja 
média é a mais alta no referido contexto. Cabe ainda ressaltar que, a volatilidade dos preços é notadamente elevada quando $i^{*}=1,2 \%$, resultado da maior frequência e intensidade das flutuações no cenário de juros altos, impactando negativamente as expectativas de demanda e deprimindo a renda. O modelo reproduz assim, um tipo de estagflação, que resulta do repasse aos preços dos custos financeiros.

Finalmente, a Tabela 4 revela que o desempenho relativo das operações de crédito (valor médio da variável $h$ ) apresenta uma relação direta com o nível da taxa básica de juros. Ou seja, quando a taxa de juros é alta, uma maior instabilidade resultante eleva o spread, o que aumenta os ganhos financeiros a partir das firmas adimplentes, ao mesmo tempo em que reduz a perda de capital bancário ao precipitar a exclusão das firmas inadimplentes. Em outros termos, o modelo parece reproduzir adequadamente o fato de que política de juros altos eleva os ganhos no setor financeiro, em detrimento do setor produtivo.

\subsection{FLEXIBILIDADE NO PROCESSO DE FORMAÇÃO DE EXPECTATIVAS}

Posturas demasiadamente defensivas por parte das firmas podem resultar em uma quantidade demandada significativamente superior à ofertada, implicando o não aproveitamento de economias de escala. Por outro lado, um excesso de otimismo, tornando a quantidade ofertada superior à demandada, pode resultar em perda de competitividade, já que um endividamento excessivo impacta positivamente o preço unitário. Enquanto na simulação 4.1 cada firma utiliza uma regra fixa para a determinação da demanda esperada, será introduzido nesse experimento um mecanismo de adaptação do processo de formação de expectativas, mediante o estabelecimento de um limite aceitável para os desequilíbrios entre oferta e demanda. Assim, determina-se que cada firma buscará uma nova regra quando a demanda e oferta divergirem em um dado percentual. Particularmente, utiliza-se o limite de 30\% de discrepância aceitável. Por simplicidade a nova regra será escolhida aleatoriamente, por cada firma, entre as opções listadas naTabela 1. Foram simulados 500 períodos cuja parametrização e condições iniciais são aquelas determinadas na Tabela 2. Os principais resultados a serem destacados podem ser observados no Gráfico 7, a seguir. 
Gráfico 7 - Nível médio de preço (Pmed) sob expectativas rígidas (item 4.1) e sob expectativas flexíveis (item 4.4)

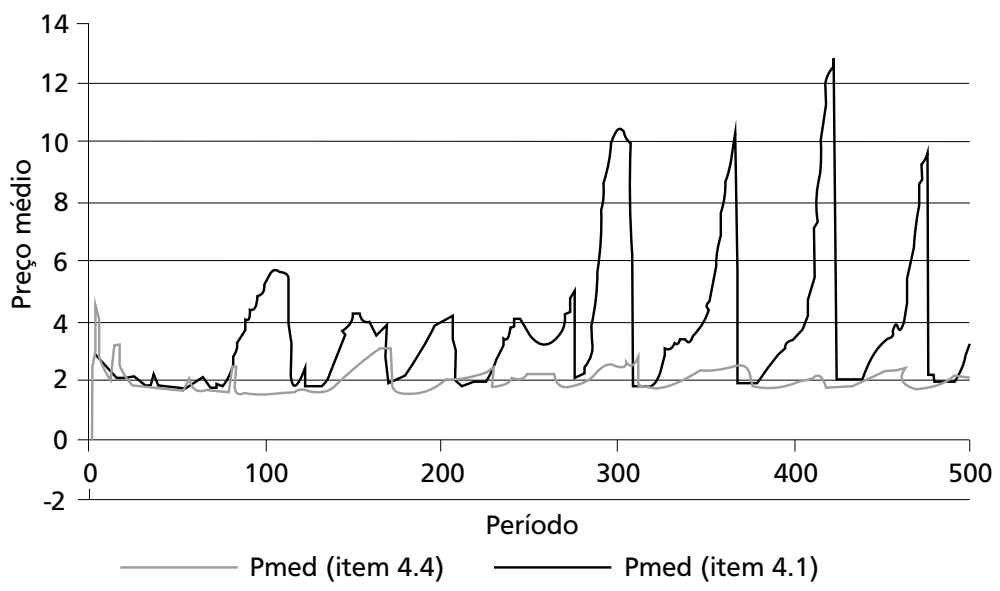

Fonte: Elaboração própria com base nos dados da simulação.

Ainda que bastante rudimentar a nova racionalidade pode ser considerada como significativamente mais eficaz; isso se comprova pela comparação entre o comportamento do nível de preços nos dois cenários em questão (Gráfico 7) - precisamente, na simulação 4.1 o desvio-padrão é de 2,21 enquanto que na simulação 4.4 é de 0,38 . Uma maior estabilidade verificada na última é resultado do comportamento das firmas, as quais se adaptam com o objetivo de elevar a sua competitividade.

Finalmente, cabe destacar que a estabilidade de preços não implica necessariamente a estabilidade do sistema como um todo. A esse respeito, a volatilidade da renda, medida pelo desvio-padrão, revelou-se inclusive maior em $4.4(206,9)$ quando comparada a $4.1(128,2)$. Esse resultado converge com a proposição de que, sistemas descentralizados, permeados por incerteza, o comportamento das variáveis agregadas não pode ser deduzido a partir do comportamento individual. A dinâmica global no presente modelo é ditada pela natureza heterogênea dos agentes, a qual é fonte permanente de não linearidades. Não obstante, as oscilações não são explosivas; mantêm-se restritas a um determinado conjunto de pontos, tornando possível a sustentação de uma estrutura básica, a qual é garantida pelo comportamento racional (ainda que limitado) dos agentes. 


\subsection{SIMULAÇÃO COM AGENTES HOMOGÊNEOS}

Esta simulação tem como objetivo avaliar alguns aspectos metodológicos referentes à hipótese de indivíduo representativo, a qual é de praxe na teoria econômica tradicional. Para tanto, o grau de assimetria apresentado na Tabela 2 será fixado em zero, ao mesmo tempo em que a formação de expectativas de demanda se realizará a partir de uma única regra dentre aquelas apresentadas na Tabela 1. Dessa forma, as firmas apresentarão homogeneidade tecnológica e expectacional. Os resultados obtidos em tais condições são, então, confrontados àqueles da simulação 4.1 .

\section{Gráfico 8 - Evolução do número de firmas no modelo com agentes homogêneos}

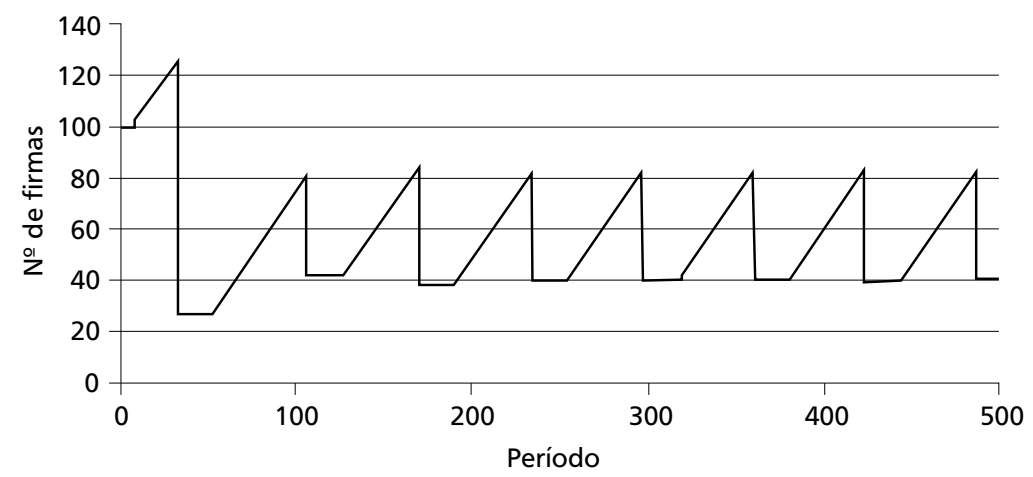

Fonte: Elaboração própria com base nos dados da simulação.

Sob a hipótese de homogeneidade o banco não tem como avaliar os projetos individualmente, de modo que só poderá optar entre os casos extremos de restrição total e oferta indiscriminada de crédito. Note que a regularidade observada no Gráfico 8 resulta deste fato, onde os referidos casos são representados, respectivamente, pelas regiões horizontais e pelas partes ascendentes do gráfico. Cabe ainda ressaltar que o comportamento oscilatório regular é uma característica de todas as demais variáveis do sistema. Os Gráficos 9, 10 e 11 permitem uma análise mais detalhada ao focalizar um movimento cíclico específico, particularmente o que ocorre entre $t=300$ e $t=370$. 
Gráfico 9 - Evolução do número de firmas

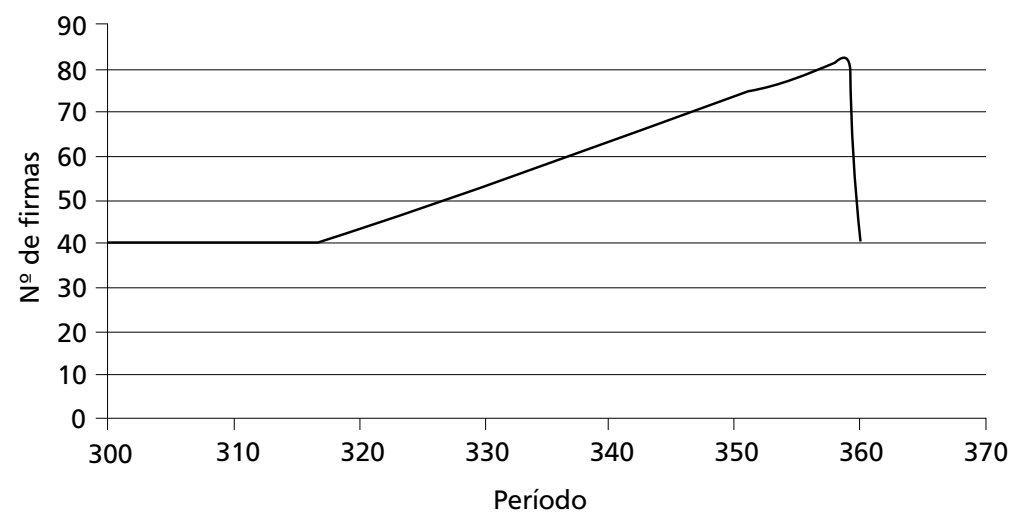

Firmas

Fonte: Elaboração própria com base nos dados da simulação.

Gráfico 10 - Desvio-padrão $(\sigma)$ do capital das firmas em operação

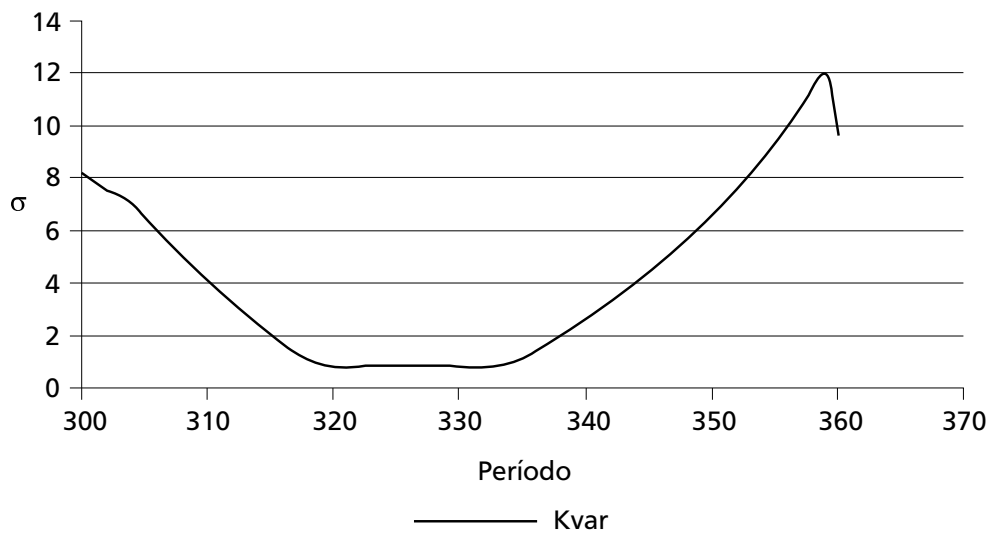

Fonte: Elaboração própria com base nos dados da simulação. 


\section{Gráfico 11 - Desvio-padrão dos preços praticados pelas firmas em operação}

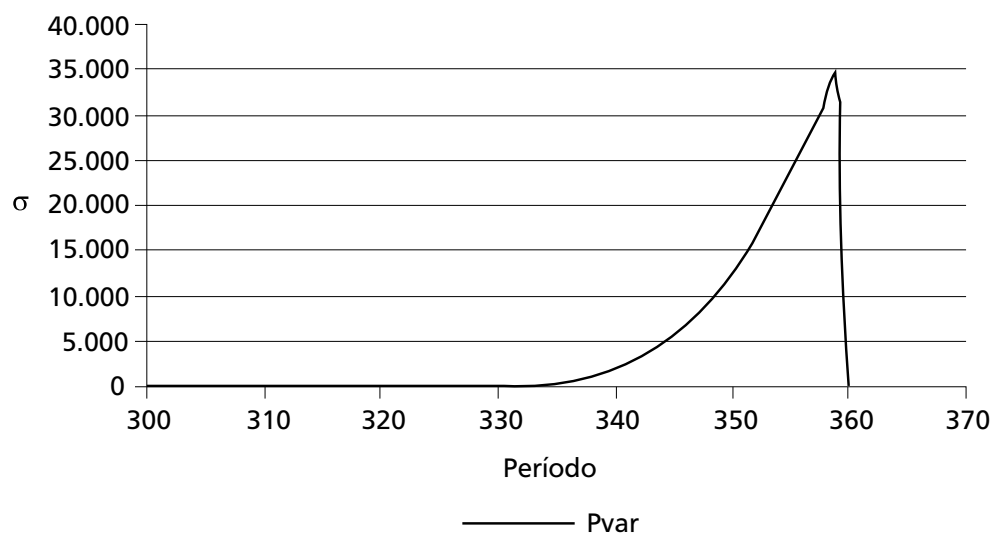

Fonte: Elaboração própria com base nos dados da simulação.

Os gráficos anteriores informam basicamente que existe uma tendência à convergência quanto ao tamanho e preços praticados pelas firmas. Isso se verifica quando o sistema opera sob restrição de crédito, o que ocorre entre os períodos 300 e 320 (Gráfico 9); nesse intervalo as dispersões de $K$ e $P$ tendem a zero (Gráficos 10 e 11, respectivamente). A elevação da dispersão ocorre quando a entrada de firmas é permitida. Sob a hipótese de homogeneidade o setor produtivo se assemelha bastante ao modelo de concorrência monopolística de Chamberlain, o qual pressupõe agente representativo e produtos simetricamente diferenciados. Em equilíbrio (da indústria), este último implica que as firmas terão o mesmo tamanho e produzirão a mesma quantidade, ao mesmo nível de preços, o que é consonante com os resultados encontrados.

\subsection{PRODUTOS HOMOGÊNEOS}

O presente exercício pressupõe que as firmas têm capacitações tecnológicas diferenciadas, porém produzem bens homogêneos. O Gráfico 12 apresenta a evolução do número de firmas nessa situação (parâmetro $A$ igual a zero para todas as firmas), e naquela da simulação 4.1 em que há diferenciação de produtos (parâmetro $A$ positivo, com média $0,5$ e desvio-padrão de 0,6$)$. 
Gráfico 12 - Evolução do número de firmas com e sem diferenciação de produtos

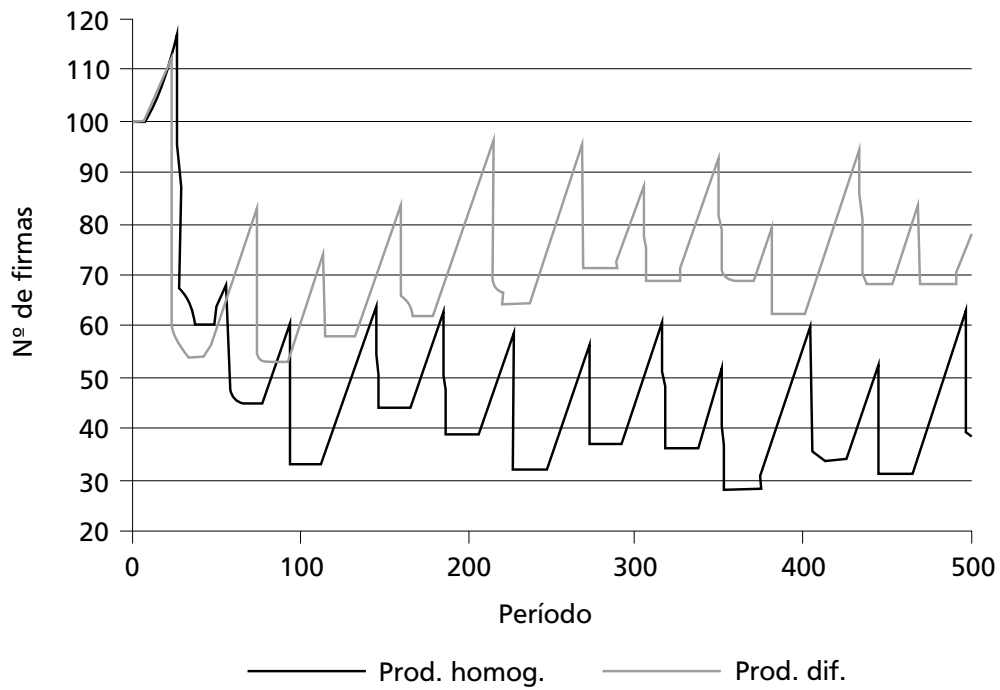

Fonte: Elaboração própria com base nos dados da simulação.

Nota-se, por meio do Gráfico 12, que, sob a hipótese de diferenciação de produtos, a média de firmas em operação é significativamente mais elevada. Observa-se ainda que, quando não há diferenciação de produtos a concorrência ocorre exclusivamente via preços (ver equação 9). Isso implica que a firma que apresentar maior eficiência tecnológica - portanto, custos mais baixos - tenderá a monopolizar o mercado mediante a fixação de um preço que impede a permanência dos concorrentes. Esse resultado é consistente com o chamado Paradoxo de Bertrand, para o caso específico em que há assimetria de custos (Tirole, 1988, p. 211). A tendência ao monopólio pode ser observada no Gráfico 13, o qual mostra que ao final de 500 interações uma única empresa detém $66,7 \%$ do capital total das firmas em operação. 


\section{Gráfico 13 - Relação entre tamanho (K) e nível de preços (P) com produtos homogêneos}

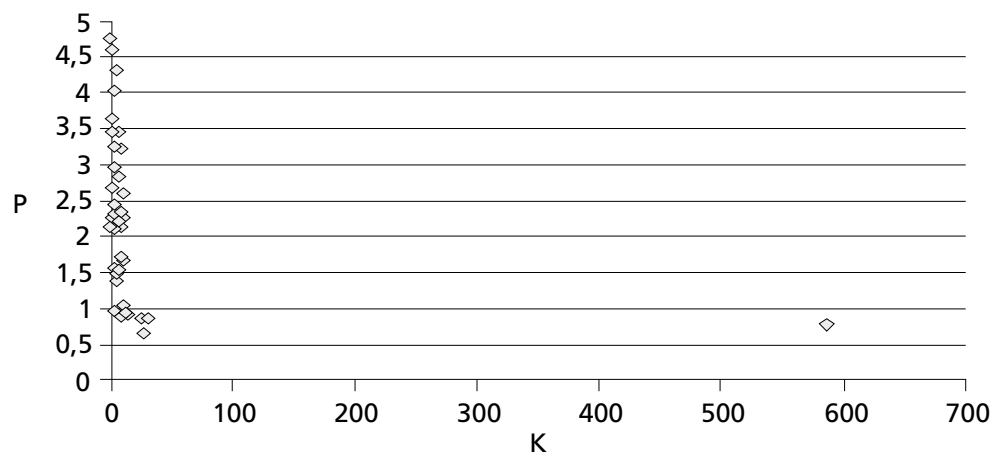

Fonte: Elaboração própria com base nos dados da simulação.

\section{CONSIDERAÇÕES FINAIS}

O presente trabalho procurou modelar a relação entre os sistemas produtivo e financeiro. Como resultado, instabilidades foram observadas como uma propriedade emergente, decorrente da heterogeneidade dos agentes, a qual foi considerada em dois sentidos: i) tecnológica: implicando desempenhos diferenciados no mercado; e ii) expectacional: na medida em que os resultados do investimento não podem ser conhecidos ex ante.

A exclusão de uma firma específica se associa, particularmente, a dois fatores: às elevadas deseconomias de escala, que se verificam quando da redução contínua da parcela de mercado (equação 7); e, aos efeitos (deletérios) cumulativos decorrentes de uma elasticidade-preço relativamente elevada, no que se refere à equação da competitividade (equação 9). A exclusão em massa, que ocorre quando o sistema atinge um dado nível crítico, é decorrência de uma rede complexa de relações não lineares entre os indivíduos e entre todas as partes constituintes do modelo, o que inviabiliza a obtenção de uma solução analítica. Esse resultado constitui uma propriedade emergente do sistema, que deve ser avaliado à luz dos fundamentos do modelo.

Do ponto de vista metodológico, uma abordagem a partir da teoria dos sistemas complexos mostra-se bastante oportuna para o desenvolvimento de modelos sob a ótica pós-keynesiana, na qual o tempo importa. Em modelos baseados em agentes, os indivíduos exploram nichos na medida em que não dispõem de conhecimento preciso sobre o sistema como um todo; isto é, a informação é localizada. Dada a presença de retornos crescentes (economias de escala, por exemplo) o comportamento específico de um agente 
(consumidor, firma, região) pode desviar o sistema daquilo que se verificaria sob a hipótese de indivíduo representativo. Note que isso só pode ser verdade se o tempo importa, já que a divergência só pode se verificar ao longo de um tempo historicamente datado.

O trabalho procurou enfatizar o papel do setor bancário na evolução do sistema. Este, ao fornecer os meios necessários para a efetivação do investimento, é parte integrante do processo, compartilhando o mesmo ambiente expectacional que os agentes produtivos. Foi possível observar que o comportamento especulativo, natural aos agentes financeiros, contribui para a determinação do padrão cíclico em duas frentes, a saber: (i) variações do spread, em função de uma percepção de fragilidade financeira do sistema, contribuem para o aumento da velocidade com que o sistema caminha para o seu ponto crítico; e (ii) o racionamento de crédito, uma reação racional em momentos de elevada instabilidade, eleva a magnitude da crise ao cercear o investimento e a renda justamente em períodos em que as expectativas de lucro se encontram em baixa. Além de estabelecer um piso relativamente mais baixo para a crise, o racionamento pode ainda postergar a retomada, uma vez que a memória da crise não se dissipa imediatamente com a recuperação da solidez financeira. Nas fases imediatamente pós-crise o sistema ainda é caracterizado por rigidez na concessão de crédito e spread elevado.

O retorno do investimento aos níveis desejáveis ocorrerá com uma defasagem em relação à recuperação da solidez financeira dado que, no contexto acima descrito, o preço de oferta do bem de capital é elevado - fruto da elevada taxa de juros de empréstimo - e o preço de demanda baixo - resultado do baixo nível de renda e do comportamento restritivo do setor bancário, que deprime as expectativas de lucro. A existência de defasagens - de $P^{b}$ com relação à $h$ e do spread $(z)$ em relação a $H$ - implica que precisaria haver uma coordenação bastante precisa entre os agentes para que o alcance de um estado estacionário fosse factível. A reação defasada é um comportamento racional, quando as decisões devem ser tomadas em um ambiente de incerteza forte, em que o tempo importa.

Finalmente, é importante ressaltar algumas limitações da presente abordagem. De modo geral, pode-se dizer que a metodologia de simulação baseada em agentes encontra-se, ainda, em estágio inicial de desenvolvimento. Diferentes abordagens coexistem, carecendo de um conjunto sólido e representativo de elementos teóricos e metodológicos consensuais. Particularmente, com respeito ao modelo ora proposto, a exploração de suas propriedades e a realização de estudos empíricos, tanto para a obtenção dos parâmetros da simulação quanto para a avaliação de seus resultados, permanecem como diretrizes para desenvolvimentos futuros. Não obstante, os resultados indicam que a referida linha de pesquisa pode constituir uma opção adequada para a uma maior compreensão dos problemas econômicos, basicamente por permitir a incorporação de hipóteses geralmente intratáveis a partir das ferramentas tradicionais de modelagem. 


\section{REFERÊNCIAS}

ARTHUR, W. B. Inductive reasoning and bounded rationality. American Economic Review, v. 84, n. 2, p. 406-411, 1994.

DAVIDSON, P. Is the current financial distress caused by the subprime mortgage crisis a Minsky moment? Or is it the result of attempting to securitize illiquid noncommercial mortgage loans? Journal of Post Keynesian Economics, v. 30, p. 669-676, 2008.

DELLI GATTI, D.; GALLEGATI, M.; RUSSO, A. Technological innovation, financial fragility and complex dynamics. In: Workshop of Economic Heterogeneous Interacting Agents, 10, Essex, United Kingdom, June 13-15, 2005.

DEQUECH, D. Incerteza num sentido forte: significado e fontes. In: PAULA, L. F.; SICSÚ, J. (Orgs.) Macroeconomia moderna: Keynes e a economia contemporânea. Rio de Janeiro: Campus, p. 88-108, 1999.

DIXIT, A.; STIGLITZ, J. E. Monopolistic competition and optimal product diversity. American Economic Review, v. 67, p. 297-308, 1977.

DOSI, G.; FAGIOLO, G.; ROVENTINI, A. Schumpeter meeting Keynes: A policy-friendly model of endogenous growth and business cycles. Journal of Economic Dynamics \& Control, v. 34, p. 1.748-1.767, 2010.

DOSI, G.; FAGIOLO, G.; NAPOLETANO, M.; ROVENTINI, A. Income distribution, credit and fiscal policies in an agent-based Keynesian model. Working Paper, Sant'Anna School of Advanced Studies, Pisa, n. 3, 2012.

DYMSKI, G. Why the subprime crisis is different: a Minskyian approach. Cambridge Journal of Economics, v. 34, n. 2, p. 239-255, 2010.

EPSTEIN, J. M. Growing adaptive organizations: an agent-based computational approach. In: EPSTEIN, J. M. Generative social science: studies in agent-based computational modeling. Princeton: Princeton University Press, 2006, p. 309-344.

FOLEY, D. K. The strange story of the economic agent. New York: New School University, Department of Economics, 2002, mimeo.

HOLLAND, J. H.; MILLER, J. H. Artificial adaptive agents in economic theory. AEA Papers and Proceedings, May, 1991.

KEYNES, J. M. A teoria geral do emprego, do juro e da moeda: inflação e deflação. São Paulo: Nova Cultural, 1985.

LIMA, G. T.; FREITAS, G. G. Debt financing and emergent dynamics of a financial fitness landscape. In: Encontro Nacional de Economia - ANPEC 2007, 35, Recife, Dez. 4-7, 2007.

MINSKY, H. John Maynard Keynes. New York: Colombia University, 1975.

MINSKY, H. Can "it” happen again? Essays on instability and finance. New York: M. E. Sharpe, 1982.

MINSKY, H. Stabilizing an unstable economy. New Haven: Yale University Press, 1986. 
PAULA, T. H. P. Instabilidade financeira no espaço: uma abordagem monetária da dinâmica econômica regional. Tese de doutorado. Centro de Desenvolvimento e Planejamento Regional, Universidade Federal de Minas Gerais, Belo Horizonte, 2009.

POSSAS, M. L.; DWECK, E. A multisectoral micro-macrodynamic model. Economia Selecta, v. 5, n. 3, p. 1-43, 2004.

RUIZ, R. M. Growing regions from the bottom up: regional economies as a self-organizing system. Doctorate thesis. Graduate Faculty of Political and Social Science of the New School University, 2003.

SILVERBERG, G. Evolutionary modeling in economics: recent history and immediate prospects. In: Workshop on Evolutionary Economics as a Scientific Research Programme. Stockholm, May, 1997.

SILVERBERG, G.; DOSI, G.; ORSENIGO, L. Innovation, diversity and diffusion: a self-organization model. The Economic Journal, v. 98, n. 393, p. 1.032-1.054, 1988.

SIMON, H. Theories of decision making in economics and behavioral science. American Economic Review, v. 49, p. 253-258, june, 1959.

TESFATSION, L. Agent-based computational economics: a constructive approach to economic theory. Handbook of Computational Economics, v. 2, p. 831-880, 2006.

TIROLE, J. The theory of industrial organization. Cambridge: MIT Press, 1988.

VARIAN, H. Microeconomics analysis. 3 ed. New York: W. W. Norton \& Company, 1992.

VERCELLI, A. Methodological foundations of macroeconomics: Keynes and Lucas. Cambridge: Cambridge University Press, 1991.

VERCELLI, A. A perspective on Minsky moments: revisiting the core of the financial instability hypothesis. Review of Political Economy, v. 23, n. 1, p. 49-67, 2011.

WILENSKY, U. NetLogo - Center for Connected Learning and Computer-Based Modeling. Evanston: Northwestern University, 1999. Disponível em: <http://ccl.northwester.edu/ netlogo/>. Acesso em: 25 fev. 2013.

WRAY, L. R. Minsky's financial instability hypothesis and the endogeneity of money. In: FAZZARI, S. M.; PAPADIMITRIOU, D. B. Financial conditions and macroeconomic performance: essays in honor of Hyman P. Minsky. Armonk: M. E. Sharpe, 1992, p. 161-180. 